\title{
تنفيذ العقوبة في ظل النظام الأساسي للمحمة الجنائية الدولية
}

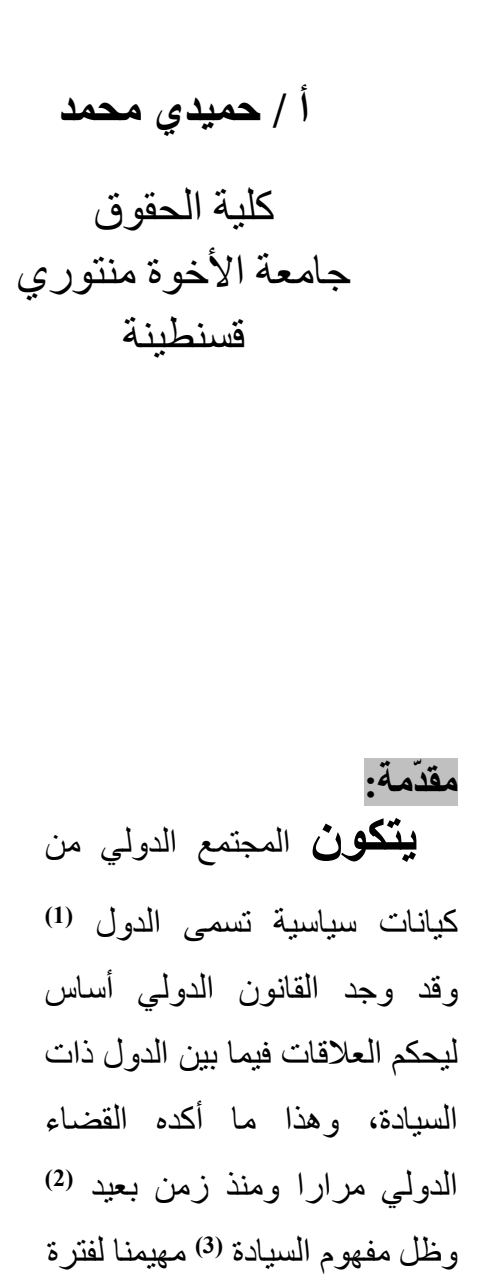




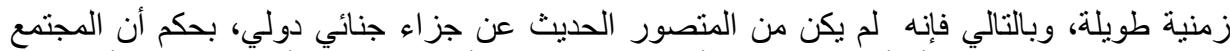
الدولي هو مجتمع تجاور أو أفقي ولهذا نجد أن قو اعده رضائية أو اتفاقية في الأساس، تستبعد أي تنظيم النيان

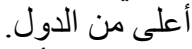
فإذا حدث وأن خرقت إحدى الدول تلأك القواعد، فإن الجزاء الذي يمكن توقيعه يقتصر على المقاطعة

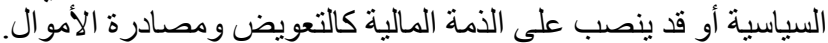

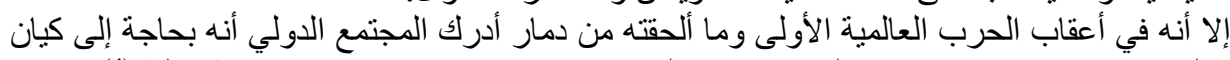

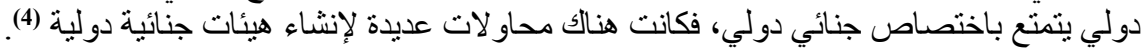

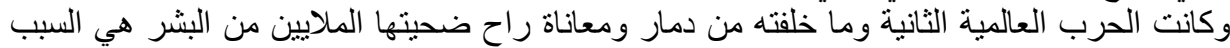

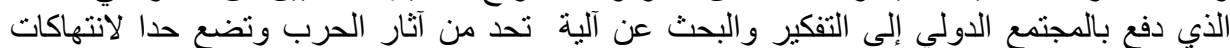

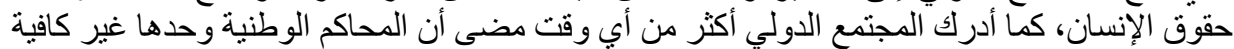

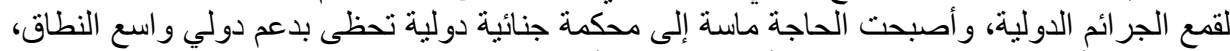

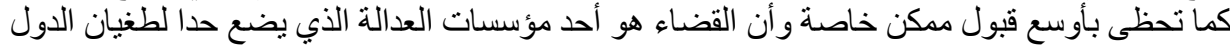

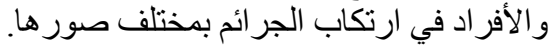

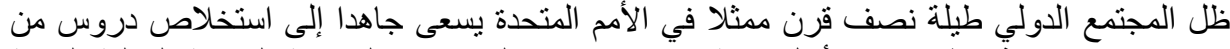

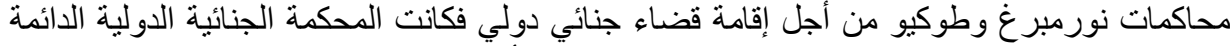

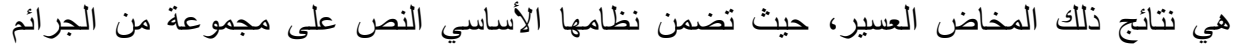

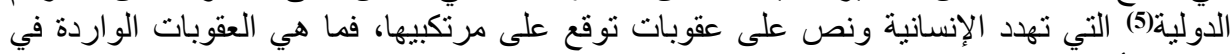

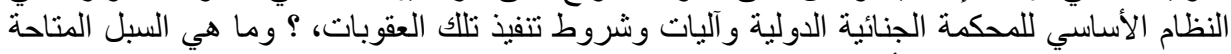
في إطار تعاون الدول لتنفيذ أحكام المحكمة الجنائية الدولية.

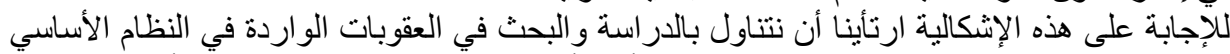

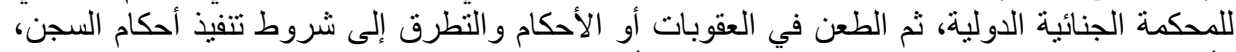

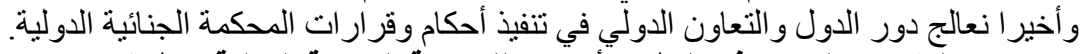

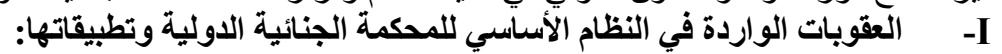

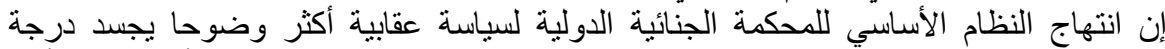

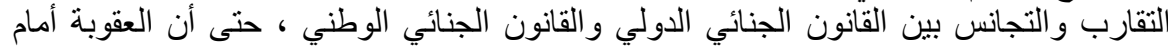

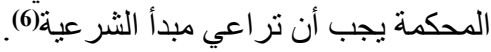

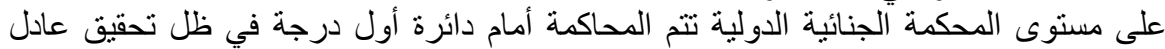

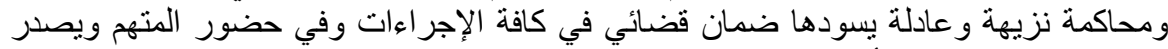
حكمها عند الاختلاف بالأغلبية (7) ونانية

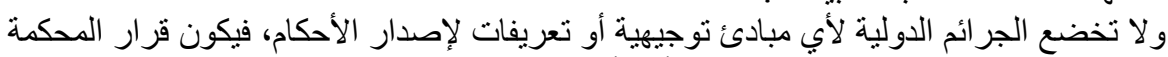

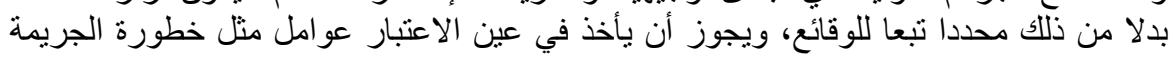

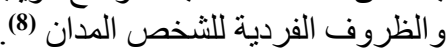
و وليه سنتطرق إلى العقوبات الواردة في النظام الأساسي للمحكمة الجنائية الدولية، ثم إلى بعض

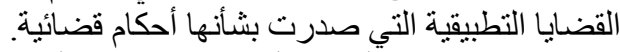

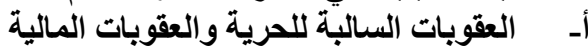

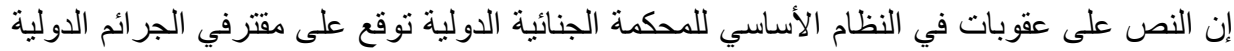

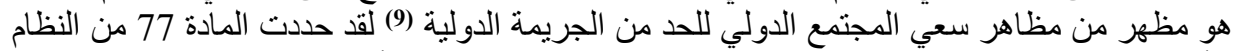

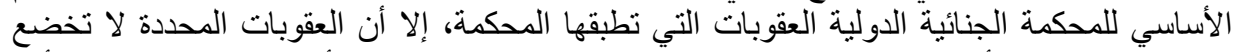

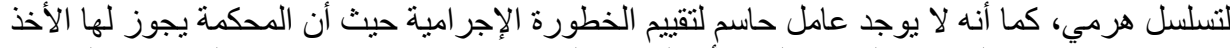

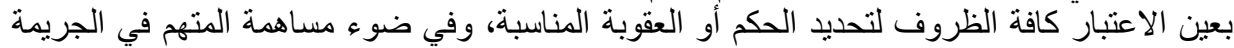

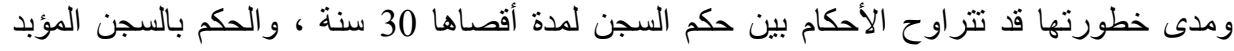


و العقوبة الوحيدة التي ينم استبعادها بشكل قاطع هي عقوبة الإعدام (10)، وهي تختلف عن تدابير الأمم

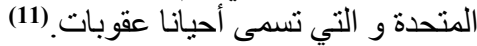
ويمكن للمحكمة أن تصدر أو امر بدفع التعويضات المنات للمني عليهم، سواء بشكل فردي أو على أساس

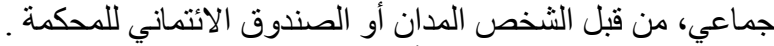
سنتطرق وفقا للمادة المذكورة أعلاه إلى العقوبات السالتية للحرية والعية العقوبات المالية على النحو التالي: 1 - 1 العقويات السالبة للحرية:

يطلق على هذا النوع عن العقوبات كذلك بالكة بالعقوبات الماسة بالحرية، حيث تتضمن إمبا حرمان

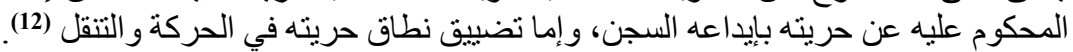

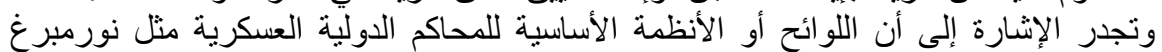

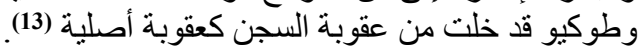

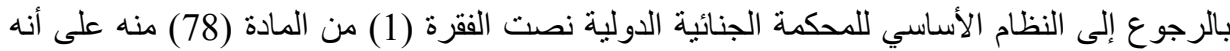

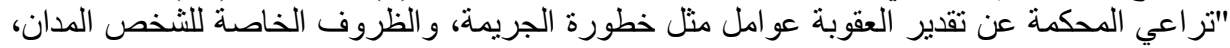

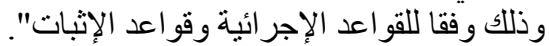

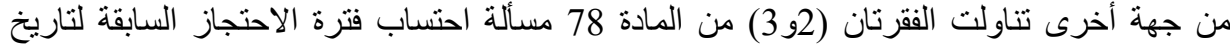

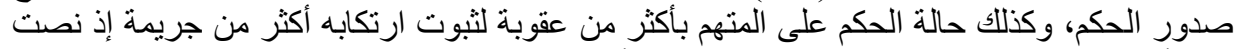

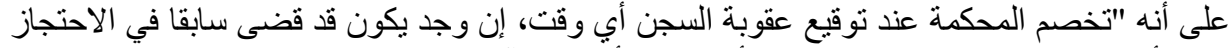

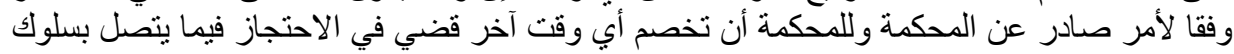

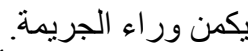

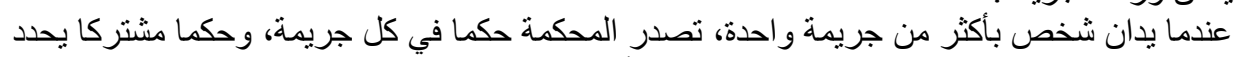

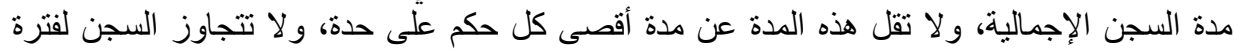

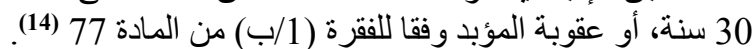

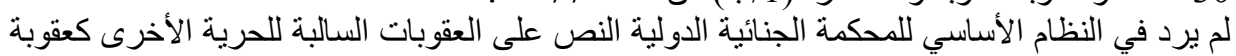

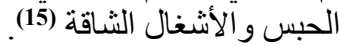

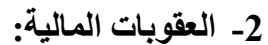

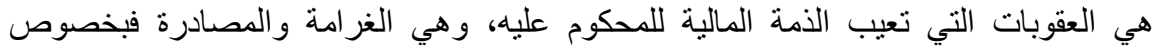

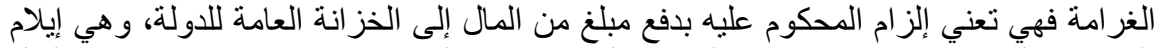
المحكوم عليه بطريق الاقتطاع من ماله، فوسيلة الإيلام في الغرامة كعقوبة هي الاقتطاع من المال المال

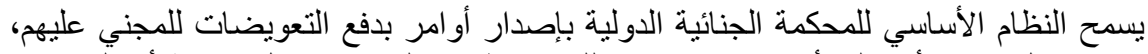

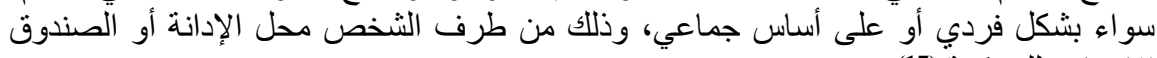

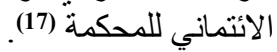

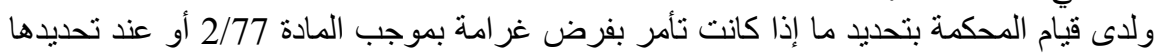

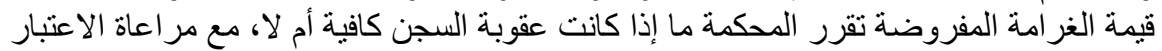

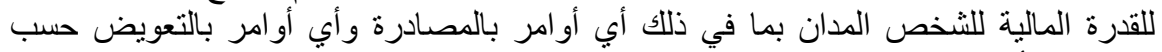

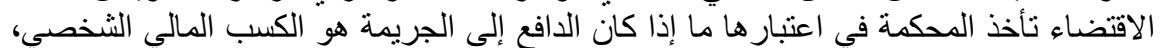

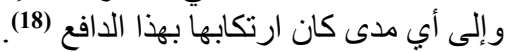

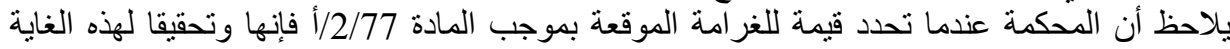

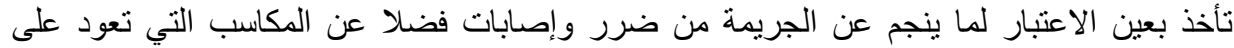
الجني من ارتكابها.

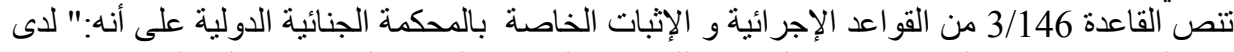

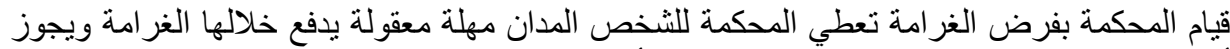
أن تسمح له بتسديدها في مبلغ إجمالي دفعة واحدة أو على دفعات خلال تلاك الفترة". 
وتتص القاعدة 4/146 على أنه يكون للمحكمة الخيار أن تحسب هذه الغرامة وفقا لنظام الغرامات

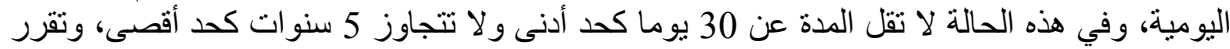

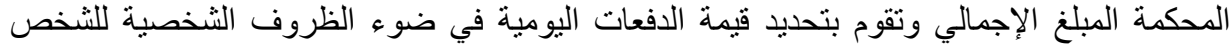

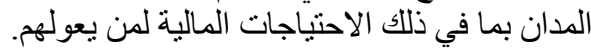

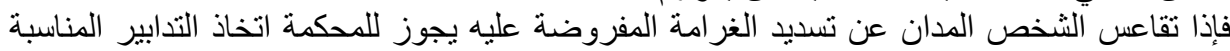

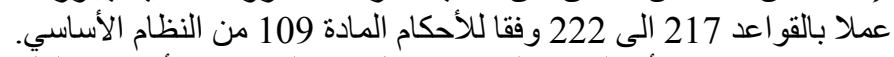

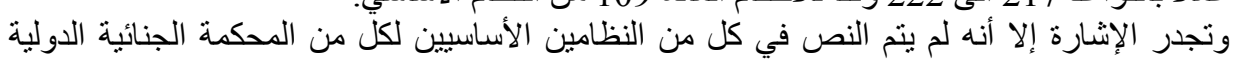

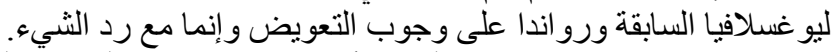

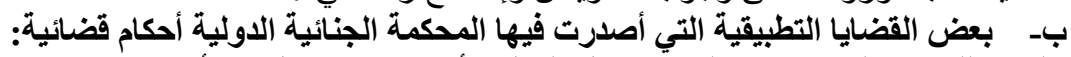

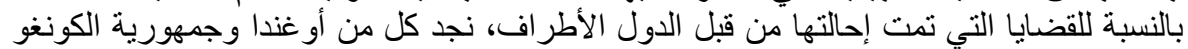
الديمقر اطية، وجمهورية إفريقيا الوسطى الوسي.

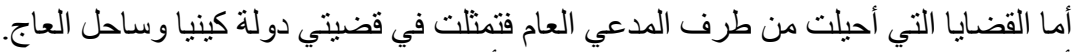

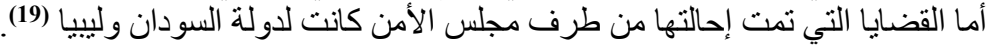

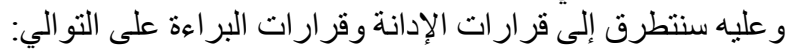
1 القرارات التي صدرت من المحكمة الجنائية الدولية بالإدانة: البانة:

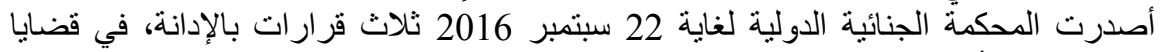

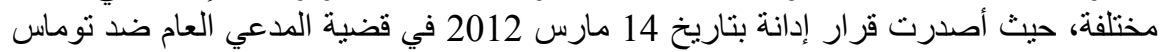

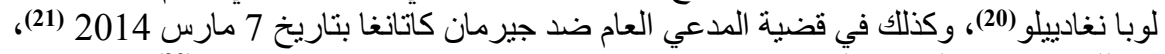

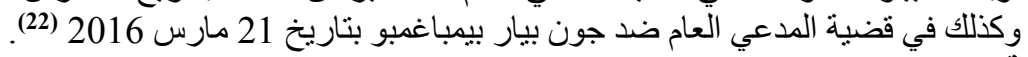

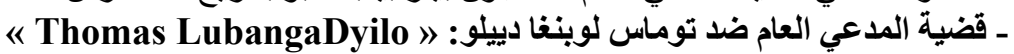

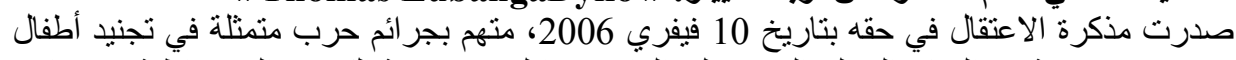

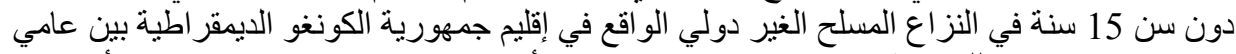

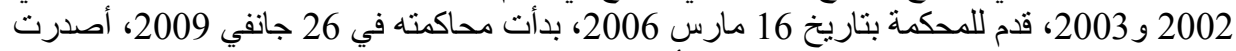

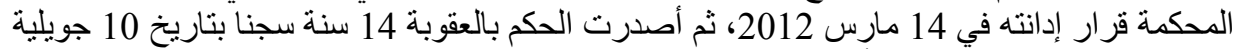
2012، حيث يعتبر هذا الحكم أول حكم صادر عن المحكمة الجنائية الدولية منذ دخولها حيز التنفيذ عام

(23) 2002

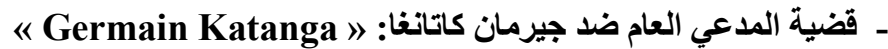

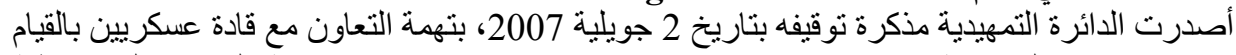

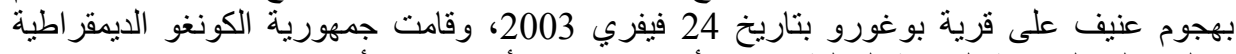

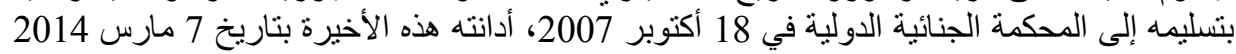

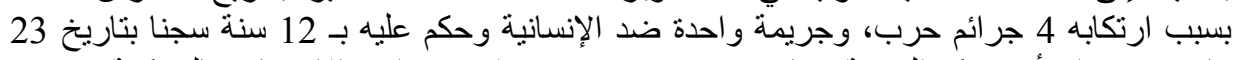

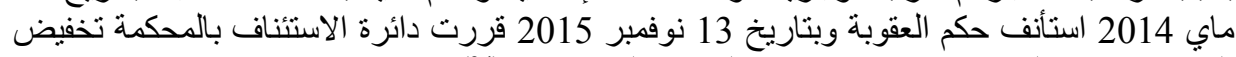

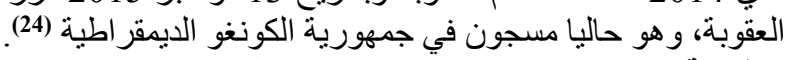

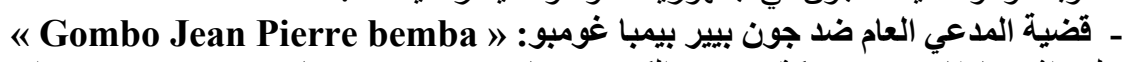

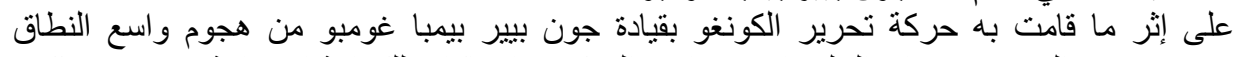

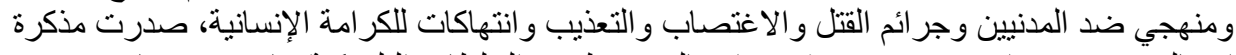

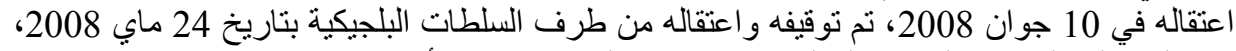

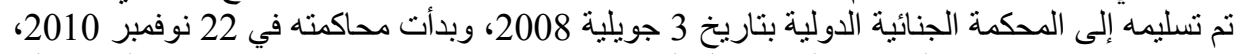

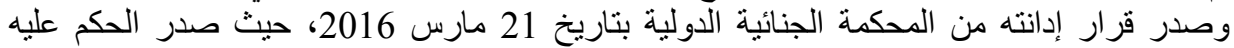

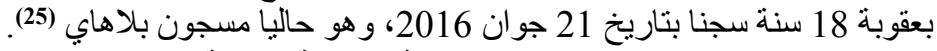

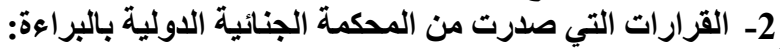

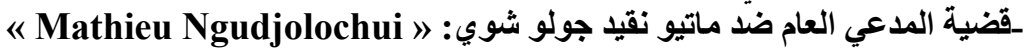




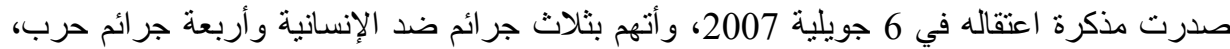

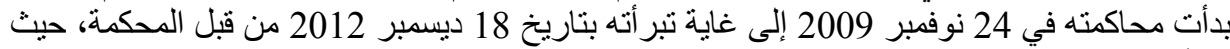
استأفت المدعي العام قرار التبرئة لكن بتاريخ 27 فيفري

الجنائية الدولية استئناف المدعي العاد العبام (26).

- II

الطعن في الحكم هو النعي عليه بمخالفة القانون أو الو اقع، وقد نظم القانون الجنائي الدولي طرقا

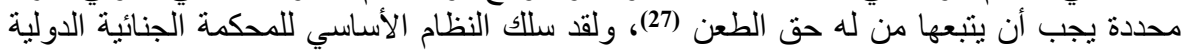

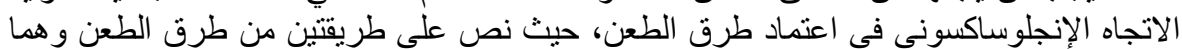

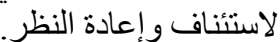

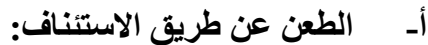

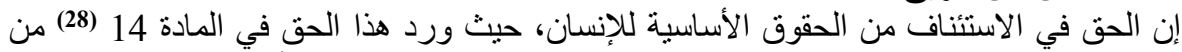

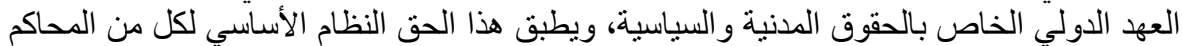

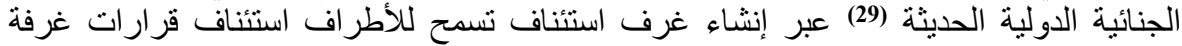
الارجة الأولى و الغرفة التمهيدية (30).

فالاستئناف(31) هو وسيلة من وسائل الطعن الاعتبادية، ويعد في حد ذاته اختبار المدى سلامة الإجر اءات المتعلقة بالمحاكمة (32).

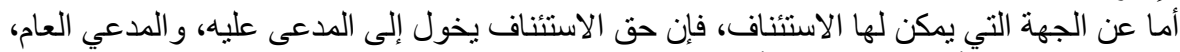

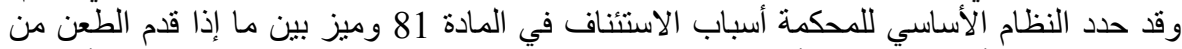

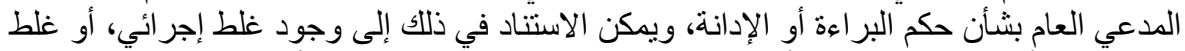

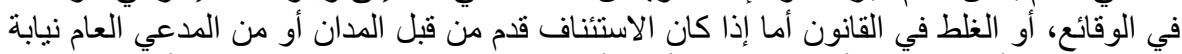

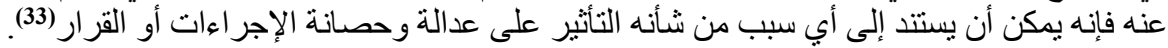

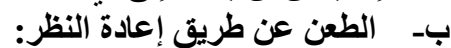

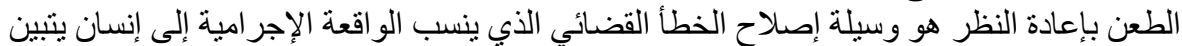

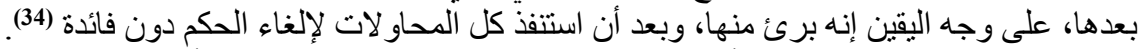

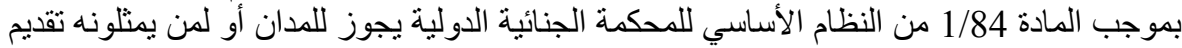

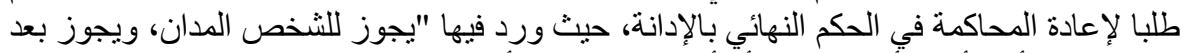

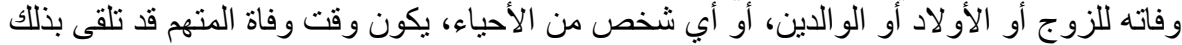

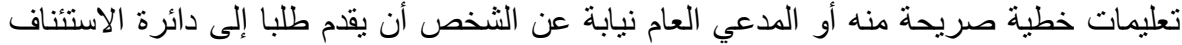

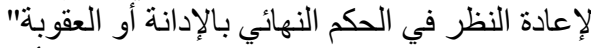
ويستند طلب إعادة ألنظر وفقا (للمادة 1/84) إلى الأسباب التالية: - - متشاف أدلة جديدة.

- - - - إذا تبين أن أدلة حاسمة تم أخذها في عين الاعتبار أثناء الإدانة ملفقة أو مزيفة أو مزورة.

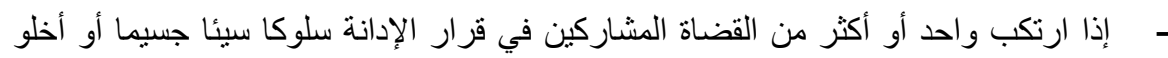

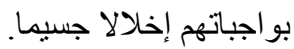
نجد أن الأسباب التي يجوز الإستناد إليها للطعن عن طريق إعادة النظر هي أوسع نطاقا في النظام

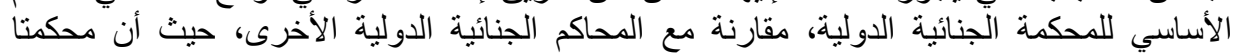

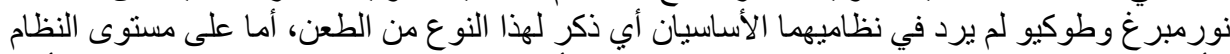

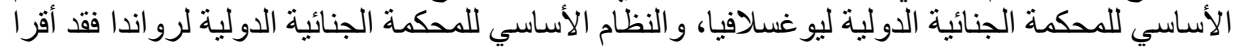

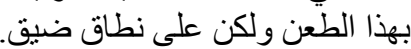
فحسب ما ورد في المادة 26 (35) من النظام الأساسي للمحكمة الجنائية الدولية ليو غسلافيا و المادة 25

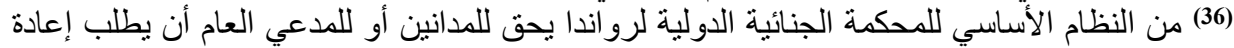

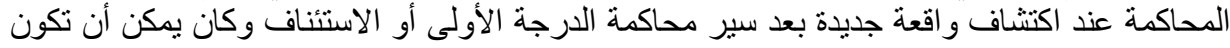


عاملا حاسما في التوصل إلى القرار، هذا بعني أن المحكمنين اعتمدتا على سبب واحد لطلب إعادة النظر وهو اكتشاف و اقعة جديدة.

تنفيذ الأحكام (العقويات):

من الأهمية بمكان تحديد مكان تتفيذ العقوبات و الثروط اللازمة لها.

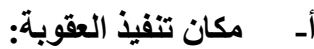

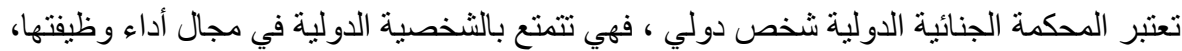

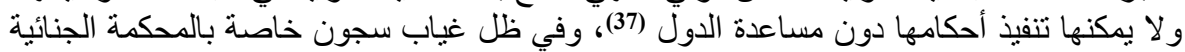

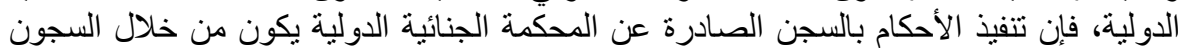

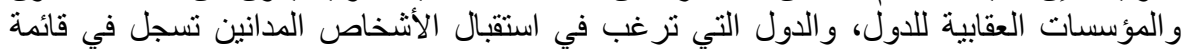

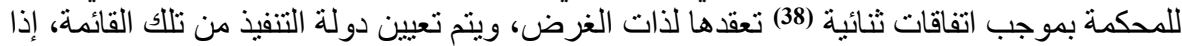

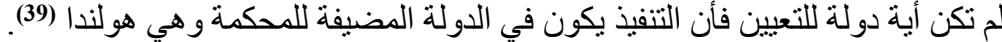

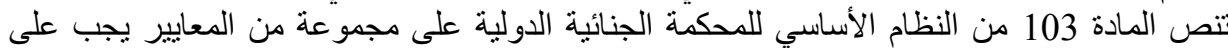

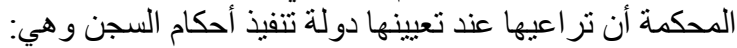

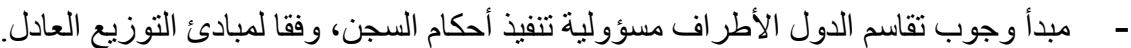

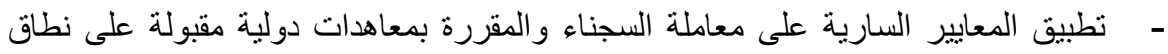
واسع. - أية عو امل أخرى تتعلق بظروف الجريمة أو الثخص المحكوم عليه أو التنفيذ الفعلي للحكم، حيثما يكون مناسبا لاى تعيين دولة التنفيذ.

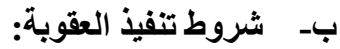

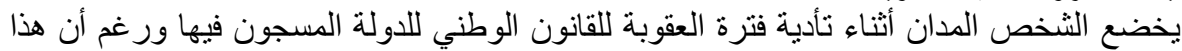

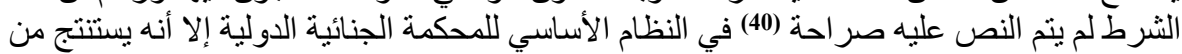

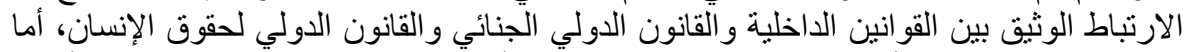

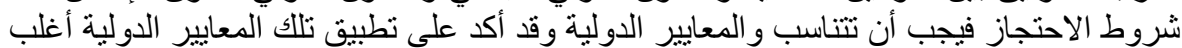

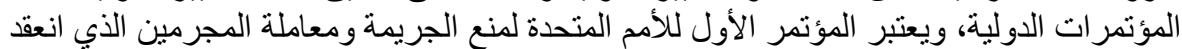

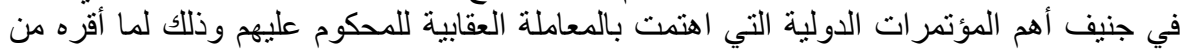

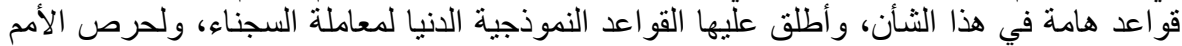

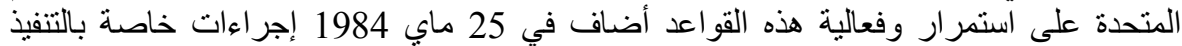
الفعال لهذه القو اعد (41).

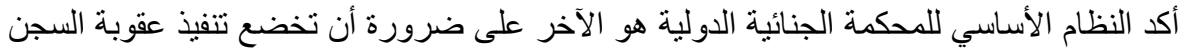

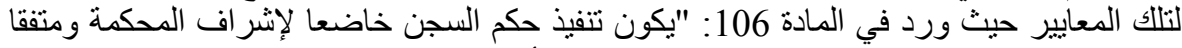

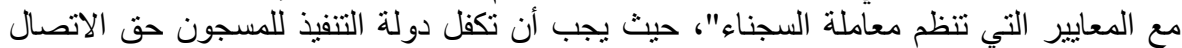

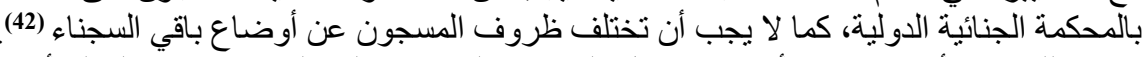

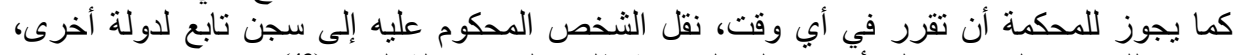

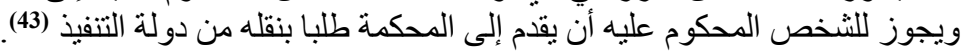

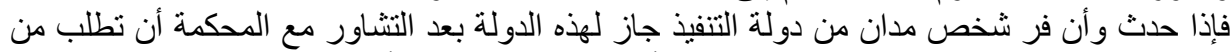

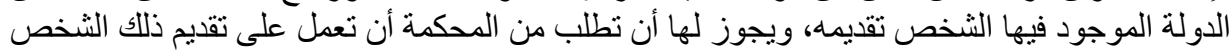

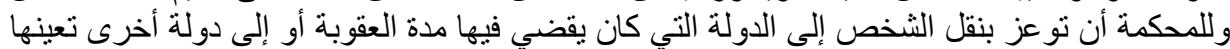
المحكمة (44).

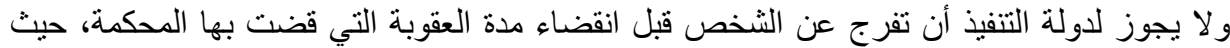

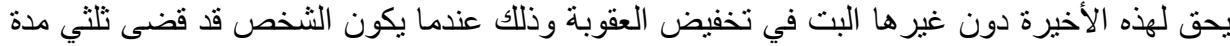


العقوبة، أو خمسا وعشرين سنة في حالة السجن المؤبد وإذا ما ثبت لديها توافر عامل أو أكثر من

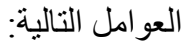

$$
\begin{aligned}
& \text { - } \\
& \text { - - ق قيام الثخص طو عا بالمساعدة على أنفاذ أحكام المحكمة. }
\end{aligned}
$$

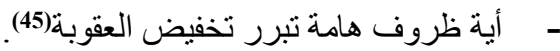

تجدر الإشارة إلى أن النظام الأساسي للمحكمة الجنائية الدولية لم يتناول بشكل واضح ومحدد قضية

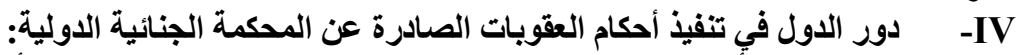

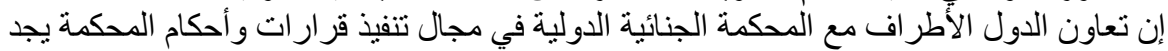

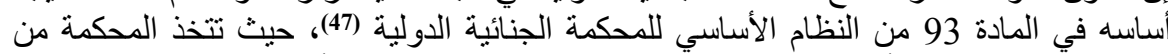

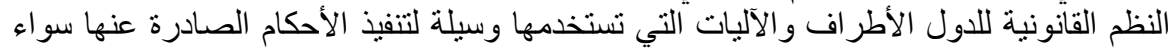

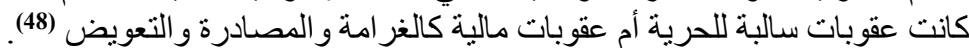

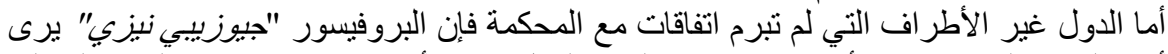

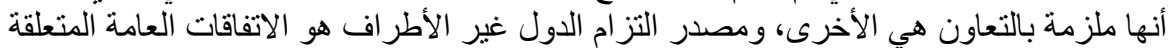

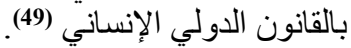
أ- ـ دور الدول في تنفيذ أحكام السجن:

عندما تقرر المحكمة فرض عقوبة السجن، وبعدة ولعد أن يكتسب القرار المتعلق بالعقوبة الدرجة القطعية،

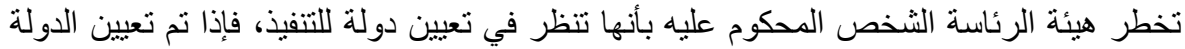

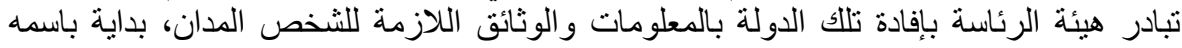

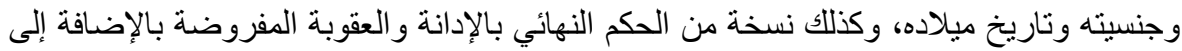

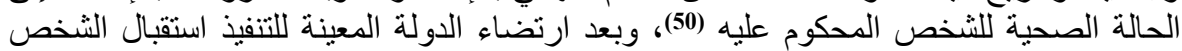

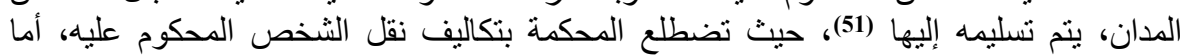
التكاليف العادية لتنفيذ العقوبة تتحملها دولة التنفيذ (52).

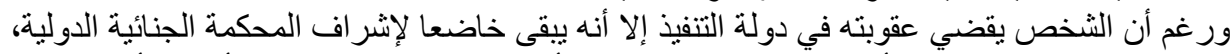

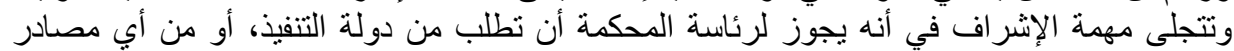

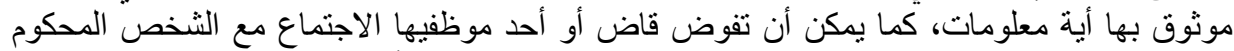

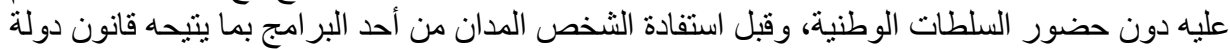

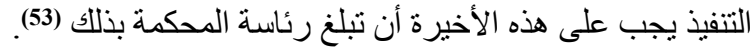
وتجدر الإثشارة إلى جانب الدول تلعب المنظمات الدولية الدور الأبرز في تعزيز تنفيذ قرارات وأحكام

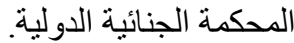
ب- دور الدول في تنفيذ أحكام الغرامة و المصادرة و التعويض:

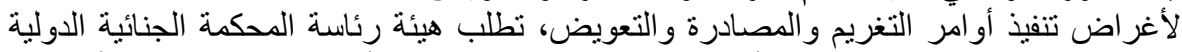

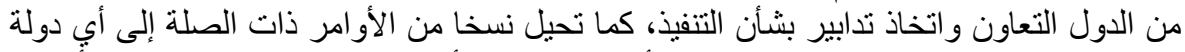

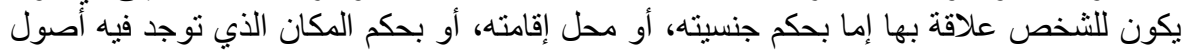
وممتلكات المحكوم عليه (54).

\section{1- دور الدول في تنفيذ أحكام الغرامة:}

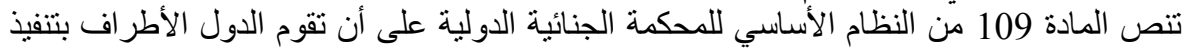

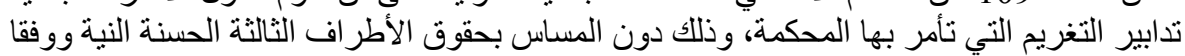

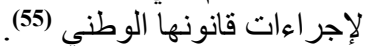

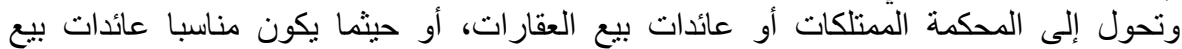
الممتلكات الأخرى التي تحصل عليها دولة طرف نتيجة لتنفيذها حكما أصدرته المحكمة الجنائية

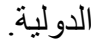


2- دور الدول في تنفيذ أوامر المصادرة:

و فقا للقاعدة 218 من قو اعد الإجر اءات وقو العاد اعد الإثبات لغرض تمكين تعاون الدول في تتفيذ أمر من أوامر المصادرة، يجب أن يحدد الأمر ما يلي: - - موية النخص الذي صدر الأمر ضده.

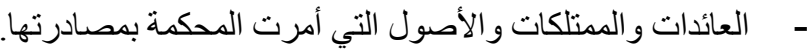

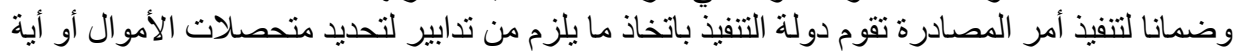

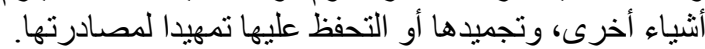

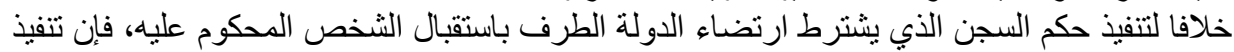

أو امر الغرامة والمصادرة لا تستلزم أن تعلن الدولة رغبتها في التعاون مع المحكمة لتنفيذ أحكامها لتهان

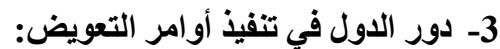

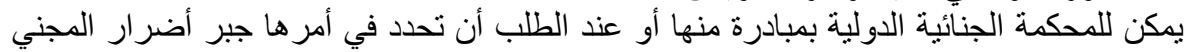

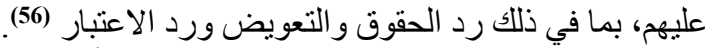

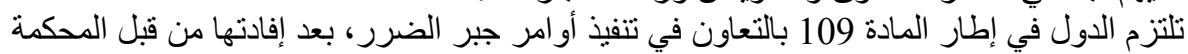

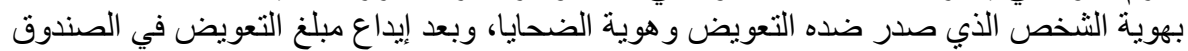

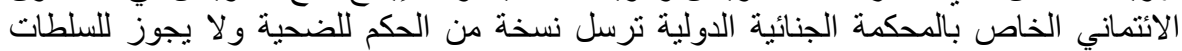
الوطنية عند تتفيذ أمر التعويض أنسكة تعدل فيه (57)

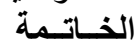

بعد أن تناولنا بالبحث الجوانب النظرية والتطبيقية لتنفيذ العقوبة في ظل النظام الأساسي للمحكمة

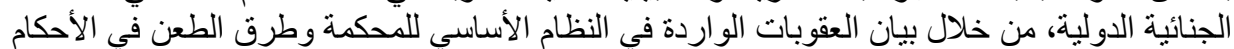

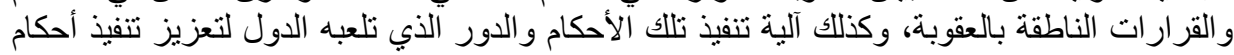
وقرارات المحكمة الجنائية الدولية نخلص إلى النتائج و التوصيات التالية:

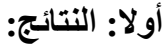

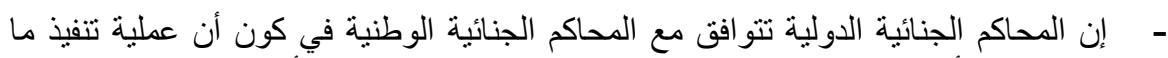

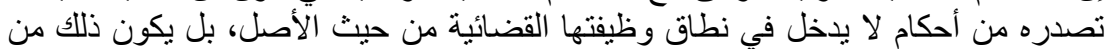

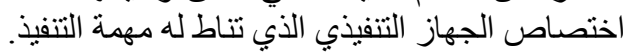

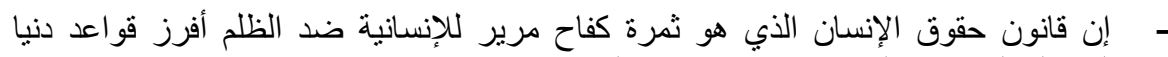

لمعاملة السجناء و الموقفين معترف بهان المها دوليا.

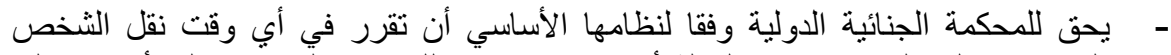

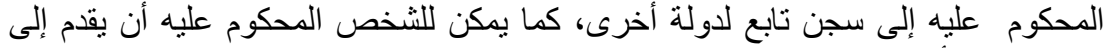
المحكمة في أي وقت طلبا بتغيير دولة التنفيذ. - - انفرد النظام الأساسي للمحكمة الجنائية الدولية بمعالجة مسألة فرار الثخص المدان من السجن.

- ـ - يعتبر تقديم الثخص الدان إلى الدحكمة الجنائية الدولية وسيلة من وسائل التعاون الدولي.

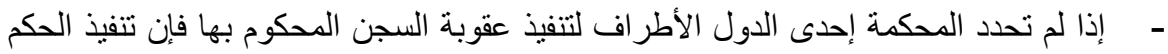

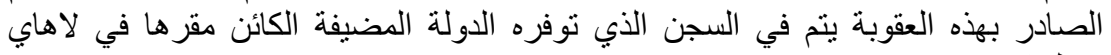
بهولندا. 


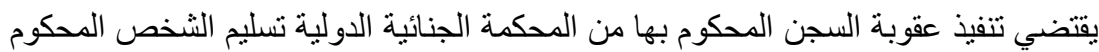

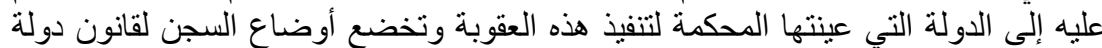
التنفيذ، ولا يتم هذا التنسليم إلا بعد أن يكتسب الحكم الصناديذ الصنادر بالإدانة الدرجة القطعية. على خلاف ما هو عليه الحال في القضاء الجنائي الوطني تفتقر الهحكمة الجنائية الدولية الدانية

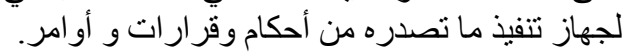

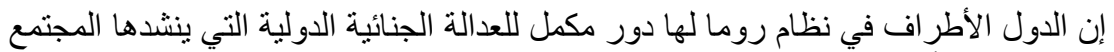

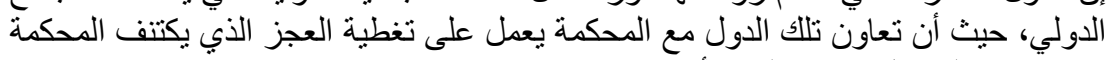

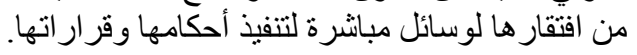

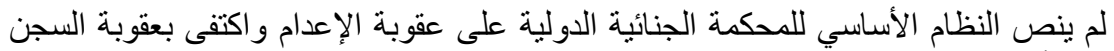
لددة أقصاها 30سنة، بالإضافة إلى العقوبات التكميلية المتمنلة في الغر امة و الدصادرة.

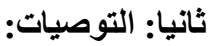

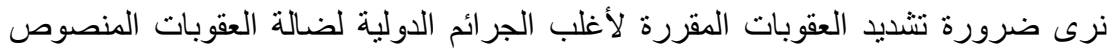

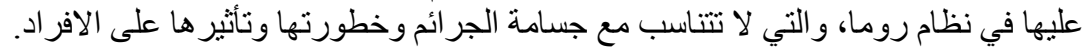

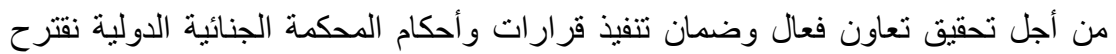

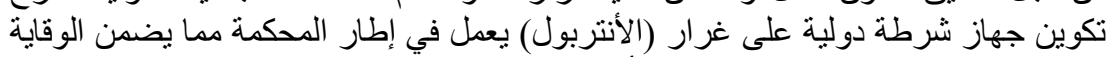

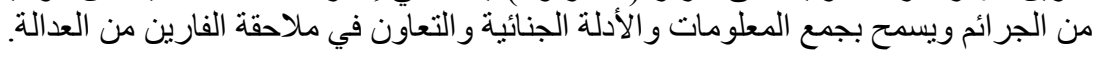

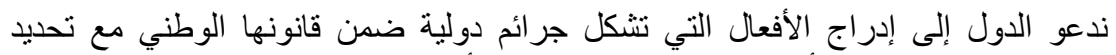
مجموعة من العقوبات أو إدراج مأدة تحيل إلى الأحكام ذات الصيل الصلة في القانون الجنائي الني الدولي.

ندعو الأشخاص للقيام طوعا بالمساعدة على إنفاذ الأحكام والأوامر الصادرة من المحكمة ويجب على كل الأطر اف تنفيذها بحسن نية.

1) محمد المجذوب، طارق المجذوب، القضاء الدولي، ط1، منشور ات الحلبي الحقوقية، بيروت، 2009، صم صند.

2) محمد يوسف علوان، القانون الدولي المعاصر، ط2 ,دار وائل للنشر، عمان، 2000م،

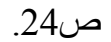

3) أنظر: محمد بوسلطان، مبادئ القانون الدولي العام، الجزء الثاني، دار الغرب، وهران،

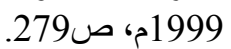

4) رغم أن تلك المحاو لات باءت بالفثل إلا أنها شكلت سو ابق هامة لإرساء دعائم قضاء جنائي دولي.

5) تقرر قو اعد القانون الدولي مسؤولية الفرد عن الجرائم التي تشكل اعتداء على الأسس التي

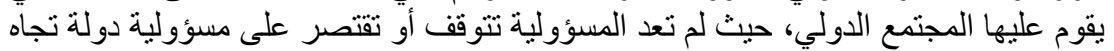

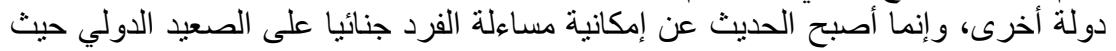

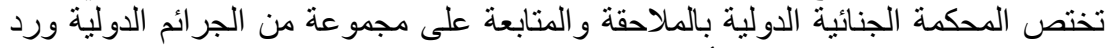

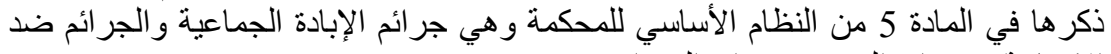
الإنسانية، وجر ائم الحرب ون وجر الئم العدوان.

6) Maria StefaniaCataleta, «Le principe de légalité de la peine en droit pénal international, points de force et de faiblesse ", La Revue des droits de l'homme [En ligne], 9 | 2016, mis en ligne le 03 mars 2016, consulté le 19 juillet 2016. URL : http://revdh.revues.org/1868 
7) أحمد أبو الوفاء، الملامح الأساسية للمحكمة الجنائية الدولية في: المحكمة الجنائية الدولية

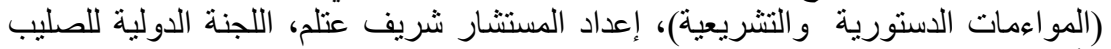

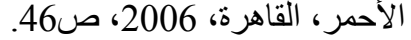

8) أنطونيو كاسيزي، القانون الجنائي الدولي -السفارة السويسرية في لبنان-، ط3، المنشورات

الحقوقية، لبنان، كونيزي،

9) محد عبد المنعم عبد الغني، الجرائم الدولية، دراسة، مقارنة في القانون الدولي الجنائي، دار

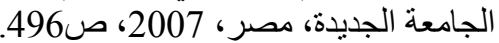

10) Rebecca Mignot-Mahdavi, La notion de peine en droit international pénal éclairée par la CPI Cour pénale internationale (Art. 76 à 78 du Statut de Rome), [En ligne], Actualités Droits-Libertés, mis en ligne le 13 juin 2014, consulté le 09 août 2016. URL : http://revdh.revues.org/838

11) Mehdi (Hamdi), Les opérations de consolidation de la paix, thèse de Doctorat, Université d'Angers, 2009, p 71.

12) بدر الدين محمد شبل، القانون الدولي الجنائي الموضوعي، دار الثقافة للنشر و التوزيع

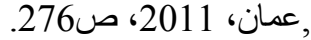

13) محمد عبد المنعم عبد الغني، القانون الدولي الجنائي، دراسة في النظرية العامة للجريمة

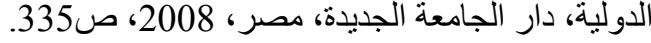

14) براء منذر كمال عبد اللطيف، النظام القضائي للمحكمة الجنائية الدولية، ط1، داء، دار الحامد

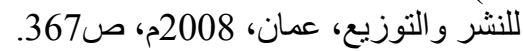

15) محمد شريف بسيوني، المحكمة الجنائية الدولية، مدخل لدار اسة أحكام و آليات الإنفاذ الوطني

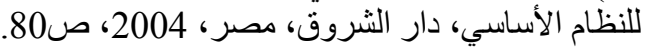

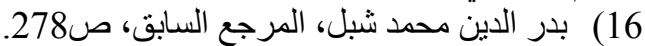

17

18

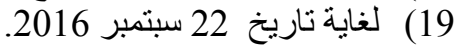

20) Affaire le procureur C.ThomasLubangaDyilo , $n^{\circ}:$ ICC-01/04/01/06, jugement rendu en application de 1'article $74 \mathrm{du}$ statut, la chambre de première instance 1 situation en République Démocratique de congo, 14 mars 2012.

21) Affaire le procureur $\mathrm{C}$ Germain Katanga, $\mathrm{n}^{\circ}$ :ICC01/04/01/07,jugement rendu en application de l'article 74 du statu, la chambre de première instance 11 situation en République Démocratique de congo, 7 mars 2014.

22) case of the prosecutor C.Jean -Pierr Bemba Gombo, ${ }^{\circ}$ : ICC-01/0501/08, judgment pursuant to article 74 of the Rome statute, trial chamber 111, situation in the central African Repiblic,21 march 2016.

23) le procureur C.ThomasLunbangaDylio, $n^{\circ}$ : ICC-01/04-01/06, Fiche d'information sur l'affaire, situation en République Démocratique du congo : http://www.icc-cpi.int/iccdocs/PIDS/publication/LubangaFRA.pdf

24) le procureur C.Germain Katanga, $n^{\circ}:$ ICC-01/04/01/07, Fiche d'information sur l'affaire, Situation en République Démocratique du congo : http://www.icc-cpi.int/iccdocs/PDIS/publicationFra.pdf 
25) le procureur C.Jean-Pirre bemba Gombo ICC-01/05-01/08 Fiche d'information sur l'affaire, Situation République centrafricaine : http://www.icc-cpi.int/iccdocs/PIDS/publication/BembaFra.pdf.

26) le procureur C.MathieuNgudjolochui, ICC-01/04-02/12, Fiche d'information sur l'affaire, Situation en République Démocratique du congo : http://www.icc-cpi.int/iccdocs/PIDS/publication/ChuiFra.pdf.

27) جهاد القضاة، الدحكمة الجنائية الدولية (درجات التقاضي وإجراءاتها)، دار وائل للنشر

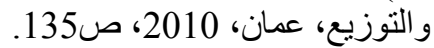

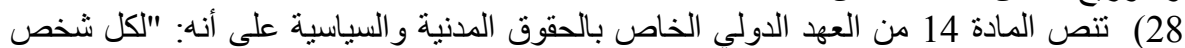

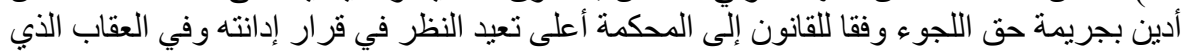

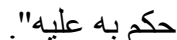

29) تجدر الإنشارة إلى أنه بالرجوع إلى النظامين الأساسيين لمحكني نورمبرغ وطن وطوكيو نجد

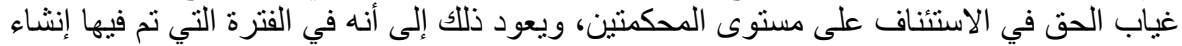
هاتين المحكمتين، لم تكن فكرة حقوق الإنسان قد تبلورت ولم تصل بعد إلى درجة التطور منلما هي التي

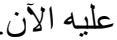

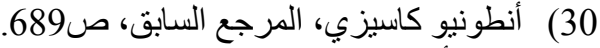

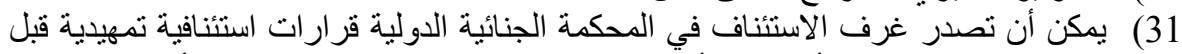

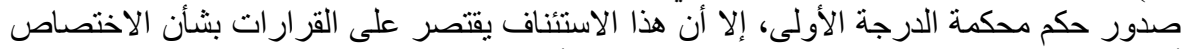

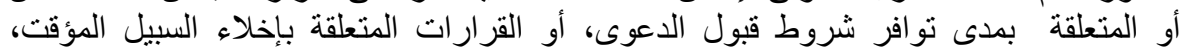

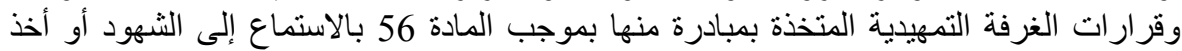

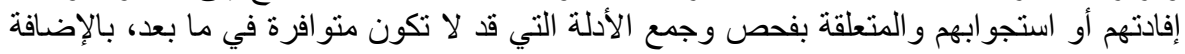
إلى القرارات التي تلزم بالتعويض.

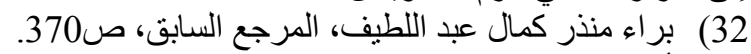
33 ) أنظر : محمد هشام فريجة، دور القضاء الدولي الجنائي في مكافحة الجريمة الدولية، أطروحة

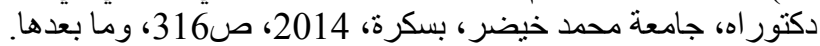
34) بهنام رمسيس، الححاكمة والطعن في الأحكام، ط1، منشأة المعارف، الإسكندرية، 1993، 289 صن

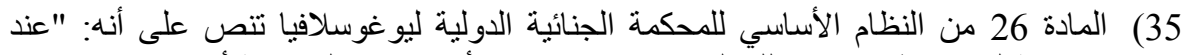

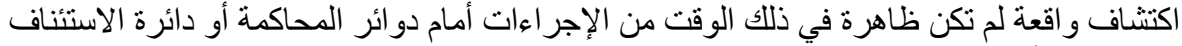

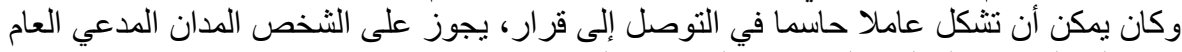

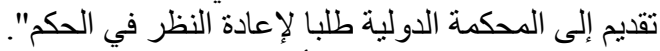

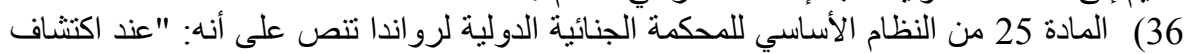

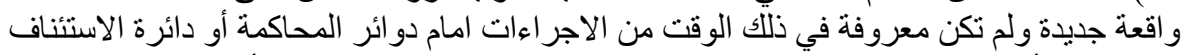

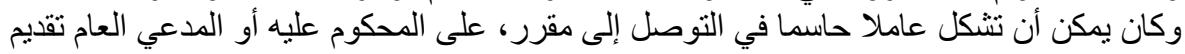

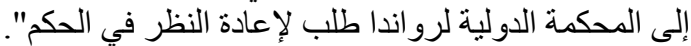

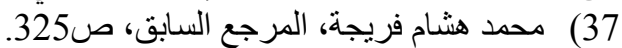
38) بادرت العديد من الدول استعدادها لاستضافة المانيا المحكوم عليهم في سجونها الوطنية، نذكر على سبيل المثال: مالي، بلجيكا، بريطانيا، النمسا.

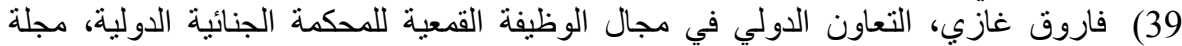

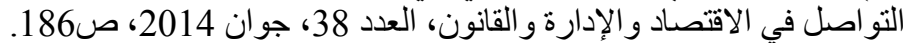

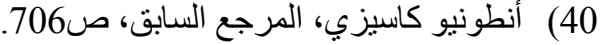


41) سليمة لدغش، دور القاضي الجزائي في تطبيق اتفاقيات حقوق الإنسان، رسالة دكتوراه،

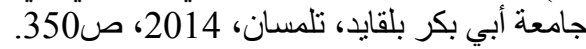

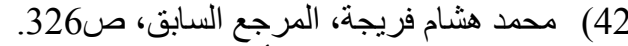

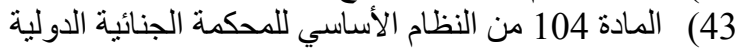
44) المادة 111 من النظام الأساسي للمحكمة الجنائية اللئية الدولية. 45) المادة 4/110 من النظام الأساسي للمحكمة الجنائية الدولية.

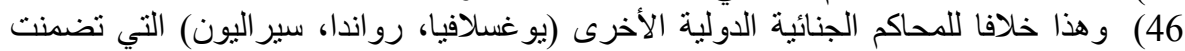

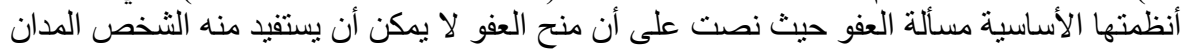

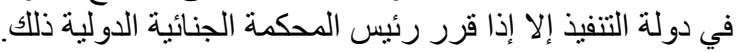
47) قبدا نجيب حمد، المحكمة الجنائية الدولية (نحو العدالية الثية الدولية)، ط1، منشورات الحلبي

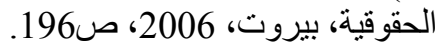

48) يوسف حسن يوسف، المحاكم الدولية وخصائصها، ط1، المركز القومي للإصدارات

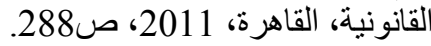

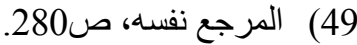
50) القاعدة 203و 204 من قو اعد الإجراءات وقو اعد الإع الإثبات.

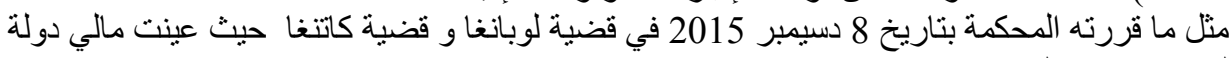
لتنفيذ عقوبات الددانين.

THE CASE OF THE PROSECUTOR v. THOMAS LUBANGA DYILO , ICC 01/04-01/06, THE PRESIDENCY SITUATION IN THE DEMOCRATIC REPUBLIC OF CONGO, Confidential with confidential annex, Decision designating a State of enforcement, 8 December 2015.

THE CASE OF THE PROSECUTOR v. GERMAIN KATANGA, ICC -01/0401/07, THE PRESIDENCY SITUATION IN THE DEMOCRATIC REPUBLIC OF CONGO, Confidential with confidential annex, Decision designating a State of enforcement, 8 December 2015.

$$
\begin{aligned}
& \text { 51) القاعدة } 206 \text { من قو اعد الإجر اءات وقو اعد الإثبات. } \\
& \text { 52 القاعدة } 208 \text { من قو اعد الإجر اءات وقاعو الاعد الإعبات. } \\
& \text { 53) القاعدة } 211 \text { من قو اعد الإجر اءات وقاعو اعد الاعد الإثبات. }
\end{aligned}
$$

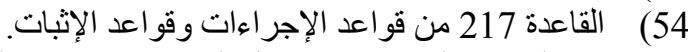

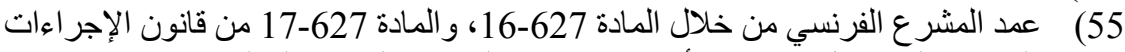

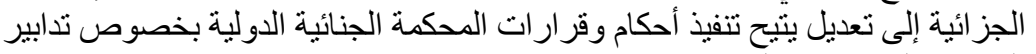

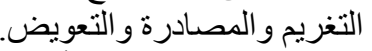
56) المادة 2/75 من النظام الأساسي للمحكمة الجنائية الدولية.

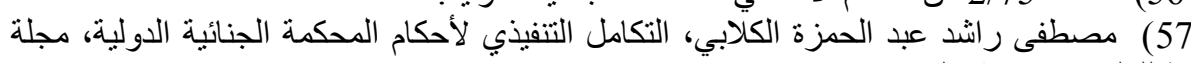

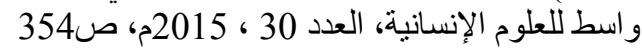

